\section{Methode, definitive}

C. Vidal ${ }^{1}$ und W.-R. Külpmann ${ }^{2}$

${ }^{1}$ Landeskriminalamt Niedersachsen, Dezernat 53 „Chemie“, Hannover, Deutschland

${ }^{2}$ Hannover, Deutschland

\section{Englischer Begriff definitive method}

Definition Methode, deren Messprinzip unmittelbar auf Basiseinheiten des SI fußt, z. B. Gravimetrie \(SI-Einheiten).
Beschreibung Unter definitiven Methoden verstand man in der Vergangenheit Methoden, die prinzipiell aufgrund ihres Messprinzips eine sehr gute Annäherung des Messwertes an den wahren Wert erlauben. Das Konzept „definitive Methode" ist aufgegeben. Man spricht jetzt in diesem Zusammenhang (aber nicht synonym) von $>$ Referenzmessverfahren der höchsten Kategorie, rückführbar auf das SI.

\section{Literatur}

McNaught AD, Wilkinson A (1997) Compendium of chemical terminology. IUPAC recommendations, 2. Aufl. Blackwell Science, Oxford 